\title{
Treatment of neuropathic pain with $5 \%$ lidocaine-medicated plaster: Five years of clinical experience
}

\author{
Claire Delorme $M D^{1}$, Marie L Navez $M D^{2}$, Valérie Legout $M D^{3}$, Rodrigue Deleens $M D^{4}$, Dominique Moyse $M D^{5}$
}

\begin{abstract}
C Delorme, ML Navez, V Legout, R Deleens, D Moyse. Treatment of neuropathic pain with $5 \%$ lidocaine-medicated plaster: Five years of clinical experience. Pain Res Manage 2011;16(4):259-263.
\end{abstract}

BACKGROUND: Neuropathic pain is often severe and adversely affects patients' quality of life.

OBJECTIVE: To perform a retrospective, observational study investigating the efficacy and safety of treating refractory chronic neuropathic pain with $5 \%$ lidocaine-medicated plaster, in patients attending pain centres. METHODS: Medical records from 467 patients treated with 5\% lidocainemedicated plaster were evaluated for efficacy (maximum and minimum pain intensities and coanalgesic consumption) and adverse events. Data from an initial assessment and at least one follow-up visit had to be available, and separate analyses were conducted for the general population and the subpopulation older than 70 years of age.

RESULTS: Of the patients enrolled, $25.0 \%$ were older than 70 years of age. While $20.6 \%$ had postherpetic neuralgia, $76.3 \%$ had other types of peripheral pain. Approximately $78.1 \%$ of cases of peripheral neuropathic pain followed surgery, and $23 \%$ were post-traumatic pain. The time from onset to referral was more than one year in two-thirds of cases. All patients experienced pain of at least moderate severity (mean $[ \pm$ SD] 11-point numerical rating scale score $5.2 \pm 2.4$ to $8.2 \pm 1.6$ ). Treatment with $5 \%$ lidocaine-medicated plaster reduced pain intensity by more than $50 \%$ in $45.5 \%$ of patients, and by at least $30 \%$ in $82.2 \%$. Of note, the consumption of analgesics and coanalgesics was significantly reduced. Results were similar in both the general population and the subpopulation older than 70 years of age, at high risk and often receiving multiple medications.

CONCLUSIONS: Treatment of refractory neuropathic pain with 5\% lidocaine-medicated plaster clearly demonstrated efficacy and an excellent safety profile in patients with refractory neuropathic pain.

Key Words: 5\% lidocaine-medicated plaster; Allodynia; Elderly patients; Localized neuropathic pain; Post-traumatic pain; Surgery

$\mathrm{N}$ europathic pain is a frequent condition in the general population, with an estimated prevalence of $5 \%$ to $7 \%$ in France, compared with $20 \%$ to $31 \%$ for chronic pain $(1,2)$.

Neuropathic pain is caused by a dysfunction of the nervous system, and is characterized by burning, tingling and/or electric shock-type pain. It may be associated with signs of nerve deficits (hypoesthesia of all types), pain caused by non-noxious stimuli (touch, thermal, dynamic or mechanical allodynia) and/or hyperpathia (an exaggerated response to a painful stimulus). The pain is generally severe and adversely affects patients' quality of life (3). Other associated comorbidities are sleep disorders, anxiety and depression, and disability.

Neuropathic pain responds to specific treatments such as tricyclic antidepressants, antiepileptics or analgesics $(4,5)$, but the efficacy of these drugs is variable and often accompanied by a poor safety profile (6). Alternatively, a topical local analgesic in the form of $5 \%$

\section{Le traitement de la douleur névropathique à l'aide d'un pansement médicamenté à la lidocaïne $5 \%$ : cinq années d'expérience clinique}

HISTORIQUE : La douleur névropathique est souvent prononcée et nuit à la qualité de vie des patients.

OBJECTIF : Procéder à une étude rétrospective d'observation sur l'efficacité et l'innocuité du traitement des douleurs névropathiques chroniques à l'aide de pansements médicamentés à la lidocaïne $5 \%$ chez des patients qui fréquentaient des centres de douleur.

MÉTHODOLOGIE : Les chercheurs ont évalué les dossiers médicaux de 467 patients traités à l'aide de pansements médicamentés à la lidocaïne $5 \%$ afin d'en évaluer l'efficacité (intensité de douleur maximale et minimale et prise de coanalgésiques) et les effets indésirables. Ils devaient disposer des données tirées d'une évaluation initiale et d'au moins une visite de suivi, et ont effectué des analyses distinctes pour la population générale et la sous-population de plus de 70 ans.

RÉSULTATS : Parmi les patients participants, 25,0\% avaient plus de 70 ans. Tandis que 20,6 \% souffraient de névralgie post-herpétique, 76,3\% souffraient d'autres types de douleurs périphériques. Environ 78,1\% des cas de douleurs névropathiques périphériques suivaient une opération, et dans $23 \%$ des cas, il s'agissait de douleurs post-traumatiques. Dans les deux tiers des cas, plus d'un an s'était écoulé entre le début des douleurs et l'aiguillage. Tous les patients souffraient de douleurs au moins modérées (indice moyen [ \pm ÉT] de l'échelle d'évaluation numérique de 11 points $5,2 \pm 2,4$ à $8,2 \pm 1,6$ ). Le traitement à l'aide de pansements médicamentés à la lidocaïne $5 \%$ réduisait l'intensité de la douleur de plus de $50 \%$ chez $45,5 \%$ des patients, et d'au moins $30 \%$ chez $82,2 \%$ d'entre eux. Il est à souligner que la prise d'analgésiques et de coanalgésiques s'en trouvait considérablement réduite. Les résultats étaient similaires dans la population générale et la souspopulation de plus de 70 ans très vulnérable qui prenait souvent de multiples médicaments.

CONCLUSIONS : Le traitement de la douleur névropathique réfractaire à l'aide de pansements médicamentés à la lidocaïne $5 \%$ démontre clairement son efficacité et un excellent profil d'innocuité chez les patients atteints de douleurs névropathiques réfractaires.

lidocaine-medicated plaster, applied for $12 \mathrm{~h}$ a day to the painful area, is effective in treating postherpetic neuralgia (PHN) (7-9). Several expert guidelines have proposed an algorithm for treating neuropathic pain for which $5 \%$ lidocaine-medicated plaster is recommended for localized pain conditions $(4,6,10,11)$.

PHN adversely affects the quality of life of elderly patients, and traditional treatments are not always compatible with age-related reductions in various vital functions (12). Topical treatments, because of their localized efficacy and low incidence of systemic adverse reactions, are very useful in this age group $(9,13)$. In France, the prescription of $5 \%$ lidocaine-medicated plaster for neuropathic pain is via a named patient program administered by the Ministry of Health. Patients must either be intolerant to, or have failed, several different treatments for neuropathic pain. Marketing authorization was recently obtained for $5 \%$ lidocaine-medicated plaster to be used

\footnotetext{
${ }^{1}$ Pain Centre, Bayeux Hospital; ${ }^{2}$ Pain Centre, Saint Etienne Hospital; ${ }^{3}$ Laboratoires Grünenthal, Levallois-Perret; ${ }^{4}$ Pain Centre, Lisieux Hospital;

${ }^{5}$ DM Consultant, Paris, France

Correspondence and reprints: Dr Claire Delorme, CH du Bessin, 13 rue de Nesmond - BP 18127, 14401 Bayeux cedex, France.

Telephone 33-231-515453, fax 33-231-515457, e-mail c.delorme@sih-bessin.fr
} 
TABLE 1

Patients' characteristics

\begin{tabular}{|c|c|c|}
\hline & $\begin{array}{c}\text { Total population } \\
(n=431)\end{array}$ & $\begin{array}{c}\text { Age }>70 \text { years } \\
\quad(n=102)\end{array}$ \\
\hline \multicolumn{3}{|l|}{ Age, years } \\
\hline$<40$ & $62(15.2)$ & - \\
\hline $40-50$ & $86(21.1)$ & - \\
\hline $51-60$ & $88(21.6)$ & - \\
\hline $61-70$ & $69(17.0)$ & - \\
\hline $71-80$ & $62(15.2)$ & $62(60.8)$ \\
\hline$>80$ & $40(9.8)$ & $40(39.2)$ \\
\hline Not recorded, $\mathrm{n}$ & 24 & - \\
\hline \multicolumn{3}{|l|}{ Sex distribution } \\
\hline Men & $156(41.2)$ & $32(36.4)$ \\
\hline Women & $223(58.8)$ & $56(63.6)$ \\
\hline Not recorded, $\mathrm{n}$ & 52 & 14 \\
\hline \multicolumn{3}{|l|}{ Time since onset of lesion } \\
\hline$<6$ months & 73 (19.5) & $21(23.6)$ \\
\hline 6 months to 1 year & $56(14.9)$ & $10(11.2)$ \\
\hline 1 to 3 years & $112(29.9)$ & $25(28.1)$ \\
\hline 3 to 5 years & $56(14.9)$ & $8(9.0)$ \\
\hline 5 to 10 years & $43(11.5)$ & $12(13.5)$ \\
\hline$>10$ years & 35 ( 9.3) & $13(14.6)$ \\
\hline Not recorded, $\mathrm{n}$ & 56 & 13 \\
\hline \multicolumn{3}{|l|}{ Treatments } \\
\hline Antiepileptics & $342(79.4)$ & $82(80.4)$ \\
\hline At least 1 antidepressant & $194(45.0)$ & $39(38.2)$ \\
\hline Tricyclic & $147(34.1)$ & 34 (33.3) \\
\hline SSRI & $69(16.0)$ & $9(8.8)$ \\
\hline \multicolumn{3}{|l|}{ Analgesics } \\
\hline Step I & $112(26.0)$ & $33(32.4)$ \\
\hline Step II & $247(57.3)$ & $65(63.7)$ \\
\hline Step III & $79(18.3)$ & $21(20.6)$ \\
\hline \multicolumn{3}{|l|}{ Etiologies } \\
\hline Central pain & $13(3.0)$ & $3(0.7)$ \\
\hline Peripheral pain & $418(97.0)$ & $99(23.0)$ \\
\hline PHN & $89(20.6)$ & $53(12.3)$ \\
\hline Post surgery & 325 (75.4) & $44(10.2)$ \\
\hline Post traumatic & $99(23)$ & - \\
\hline Cancer treatment related & $32(7.4)$ & $2(0.5)$ \\
\hline Others & $4(0.9)$ & \\
\hline \multicolumn{3}{|l|}{ Allodynia (n=243) } \\
\hline Thermal (hot/cold) & $8(3.2)$ & \\
\hline Dynamic mechanical & $179(73.6)$ & \\
\hline Both & $56(23.0)$ & \\
\hline \multicolumn{3}{|l|}{ Sensory disorders $(n=168)$} \\
\hline Hypoesthesia & $139(82.7)$ & \\
\hline
\end{tabular}

Data presented as $n(\%)$ unless otherwise indicated. PHN Postherpetic neuralgia; SSRI Selective serotonin reuptake inhibitor

for the symptomatic relief of neuropathic pain associated with herpes zoster infection; its efficacy in this condition led physicians to propose its use in other types of neuropathic pain (14-16). The chosen indications were localized neuropathic pain, and pain in which allodynia predominates and is difficult to relieve.

The purpose of the present investigation was to study clinical practice patterns in the treatment of localized refractory neuropathic pain, for which the $5 \%$ lidocaine-medicated plaster represents a new alternative with benefits outweighing risks. This encouraged us to broaden the scope to other etiologies of localized neuropathic pain. Topical treatment in pain centres was analyzed to:

- describe the population and type of neuropathic pain observed;

- evaluate the duration, efficacy and safety of treatment; and

- specify the concomitant administration of coanalgesic and other antineuropathic drugs that may interfere with comorbidity.

\section{METHODS}

The present study was a retrospective observational investigation of patients with refractory neuropathic pain who had been treated in pain centres, between 2001 and 2006, with 5\% lidocaine-medicated plaster (Versatis, Grünenthal GmbH, Germany). Each self-adhesive plaster measures $10 \mathrm{~cm} \times 14 \mathrm{~cm}$ and contains $700 \mathrm{mg}(5 \% \mathrm{w} / \mathrm{w})$ of lidocaine. It is applied to intact, dry, nonirritated skin for a period of no longer than $12 \mathrm{~h}$. When the maximum recommended dose (three plasters) is applied, approximately $3 \pm 2 \%$ of the total applied lidocaine dose becomes systemically available. This produces a local analgesic effect by the stabilization of neuronal membranes, which is believed to cause downregulation of sodium channels.

Inclusion criteria were as follows: male or female older than 18 years of age; consulting a specialized centre for localized neuropathic pain; a history of treatment failure due to insufficient efficacy or poor tolerability of previous therapy; and requiring regular application of $5 \%$ lidocaine-medicated plaster. Medical records had to be available, with an initial evaluation and at least one follow-up visit, at which the maximum and minimum pain intensity reached per day had been recorded. Cases with insufficient information to provide an accurate clinical picture or response to treatment were excluded.

A standardized grid was drafted and tested in three centres. This grid comprised the following:

- Demographic details.

- Clinical and diagnostic aspects of neuropathic pain: etiology, period of time since onset, duration, severity assessed using a visual analogue scale or numerical rating scale (NRS), concomitant symptoms (allodynia, sensory disorders), and previous analgesic treatments (two questionnaires were often used: the McGill Pain Questionnaire used in the validated French version - the Questionnaire Douleur Saint Antoine [QDSA; 17,18] - and the DN4 Questionnaire used from 2005 [19])

- Evaluation of efficacy (maximum and minimum pain intensities assessed on either a visual analogue scale or an NRS, and coanalgesic consumption).

- Evaluation of any adverse effects in patients treated with 5\% lidocaine-medicated plaster.

Data were collected by eight investigators in July 2007. Authorization was granted by the National Ethics Consultative Committee, which is responsible for all hospitals in France, and the French Commission for Data Processing, Data Files and Individual Liberties. The statistical study was primarily descriptive. The Mantel-Haenszel method was used to evaluate the impact of age on the various parameters. Changes from previous therapies and coanalgesics, before and after treatment with the 5\% lidocaine-medicated plaster, were evaluated by McNemar's test on both the general population and the subpopulation older than 70 years of age. The analysis was performed using SAS version 9.1.3 (SAS Institute Inc, USA) for Windows (Microsoft Corporation, USA). The quality and the consistency of clinical data were reviewed independently.

\section{Populations studied}

\section{RESULTS}

Eleven centres, including one academic hospital and a regional pain network of 10 centres, participated in the study. They represent a population of two million people, and cover both rural and urban areas. Recruitment was evenly distributed among centres. A total of 431 of 467 dossiers of identified patients could be evaluated. The remaining 36 dossiers were excluded because they contained insufficient information about diagnosis or the evaluation of efficacy. Most patients were older than 40 years of age $(84.7 \%)$ and $25.0 \%$ were older than 70 years of age. A total of $58.8 \%$ of the study population were women and $41.2 \%$ were men (Table 1 ). Most patients $(58.0 \%)$ were unemployed. Similar numbers of patients were referred to the pain centres by general practitioners $(49.7 \%)$ and by specialists $(50.3 \%)$, one-half of whom $(53.0 \%)$ 


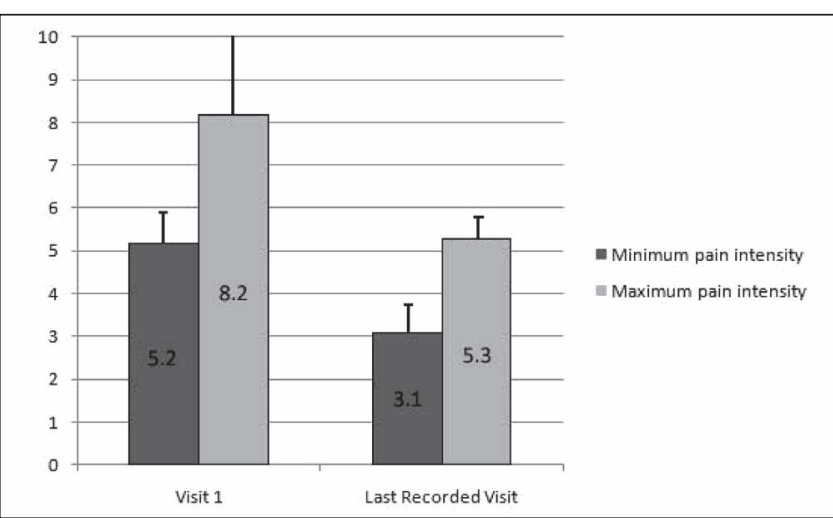

Figure 1) Evolution of pain intensity from the beginning of treatment to the last recorded assessment. Maximum and minimum pain assessments (visual analogue scale or numerical rating scale) were harmonized to an 11 -point ( 0 to 10 inclusive) numerical rating scale. The last recorded assessment corresponds to the end of the survey

were surgeons. Elderly patients were mainly referred by general practitioners and young people by consultant orthopedists.

Type of neuropathic pain (Table 1)

Neuropathic pain was diagnosed during the interview, using both a clinical examination and a questionnaire. For the 331 patient dossiers that included the QDSA, the items electric shock, burning pain, tingling and crushing were reported by $68.3 \%, 66.5 \%, 41.4 \%$ and $25.4 \%$ of cases, respectively. These items were associated in $73.4 \%$ of the patients, particularly electric shock and burning pain. The DN4 score was calculated in 81 patients; it was positive (ie, greater than 4) in 78 patients (96.2\%), including 14 of 16 patients older than 70 years of age. Sensory disturbances were reported by $38.9 \%$ of patients (168/431): $82.7 \%$ of these (139/168) suffered mainly from hypoesthesia. Evoked pain (allodynia) was identified in 56.3\% (243/431) of the patients, the predominant type being dynamic mechanical allodynia: $73.6 \%(179 / 243)$.

Etiology of neuropathic pain

Eighty-nine patients $(20.6 \%)$ had PHN. More than three-quarters of the patients $(n=329 ; 76.3 \%)$ experienced other types of peripheral neuropathic pain. Postoperative pain - mainly following orthopedic surgery of the upper and lower limbs, but also visceral or spinal surgery - was present in 325 patients $(75.4 \%)$ with peripheral neuropathic pain, while 99 patients $(23 \%)$ had post-traumatic neuropathic pain. Conversely, only 32 cases $(7.4 \%)$ were related to cancer treatment and there was one case of diabetic peripheral neuropathy. Pain of central origin (13 patients; $3.0 \%$ ) included the sequelae of strokes and spinal cord lesions, with the $5 \%$ lidocaine-medicated plaster applied over a restricted allodynic area (Table 1).

\section{Clinical characteristics}

The time since onset of the initial lesion responsible for the pain was more than one year in $65.6 \%$ of cases and more than three years in $35.7 \%$ (Table 1). The duration of pain was less than one year in $38.3 \%$ of patients, from one to three years in $30.2 \%$ and more than three years in $31.3 \%$. In patients older than 70 years of age, $62.7 \%$ had experienced pain for more than one year. The intensity of pain before the institution of topical treatment ranged from a minimum of $5.2 \pm 2.4$ to a maximum of $8.2 \pm 1.6$ on an 11-point NRS (Figure 1).

\section{Previous analgesic treatments}

Of the total number of patients in the study, $26.0 \%$ had been prescribed WHO step I analgesics, 57.3\% step II and 18.3\% step III. A tricyclic antidepressant had been prescribed in $34.1 \%$ of cases, an antiepileptic in $79.4 \%$ and a selective serotonin reuptake inhibitor in $16.0 \%$. Transcutaneous neurostimulation was used in $36.0 \%$ of cases
TABLE 2

Decrease in pain intensity* between beginning of treatment and last recorded assessment

\begin{tabular}{lcc}
\hline \% decrease & Total population $(\mathbf{n}=\mathbf{4 3 1})$ & Age $>$ 70 years $(\mathbf{n}=\mathbf{1 0 2})$ \\
\hline 0 & $22(7.5)$ & $8(11.8)$ \\
$1-29$ & $30(10.2)$ & $3(4.4)$ \\
$30-50$ & $108(36.7)$ & $20(29.4)$ \\
$51-75$ & $78(26.5)$ & $23(33.8)$ \\
$76-100$ & $56(19.0)$ & $14(20.6)$ \\
Not recorded, $n$ & 137 & 34 \\
\hline
\end{tabular}

Data presented as $n$ (\%) unless otherwise indicated. ${ }^{*}$ Pain intensity $=$ maximum pain intensity experienced over a $24 \mathrm{~h}$ period

and other therapies (pharmacological or nonpharmacological) in $37.4 \%$ of cases. Most patients $(81.9 \%$ ) had received between two and five different treatments before the institution of $5 \%$ lidocainemedicated plaster. In patients older than 70 years of age, $32.4 \%$ took step I, $63.7 \%$ step II and $20.6 \%$ step III analgesics. A tricyclic antidepressant was prescribed in $33.3 \%$ of cases and an antiepileptic in $80.4 \%$ of cases. Transcutaneous neurostimulation was applied in $31.4 \%$ of cases. Several treatments were sometimes combined.

\section{Treatment}

The survey revealed that the mean duration of treatment with $5 \%$ lidocaine-medicated plaster was less than three months in $42.1 \%$ of cases ( $45.5 \%$ in patients older than 70 years of age), between three and 12 months in $36.9 \%$, and more than one year in $21.1 \%(22.7 \%$ in patients older than 70 years of age). The dosage was one plaster daily in $74 \%$ of patients $(80.7 \%$ in patients older than 70 years of age) and two plasters daily in $13.5 \%$ of the total population $(12.5 \%$ in patients older than 70 years of age). At the end of the investigation, $59.6 \%$ of the patients continued treatment with $5 \%$ lidocaine-medicated plaster.

Efficacy was evaluated from the change in pain intensity between the beginning of treatment and the last recorded assessment (corresponding to the end of the survey), as well as changes in medication use (analgesics and coanalgesics for neuropathic pain). There was a statistically significant decrease in mean pain intensity: from $5.2 \pm 2.4$ to $3.1 \pm 2.5$ $(\mathrm{P}<0.001)$ for the minimum value, and $8.2 \pm 1.6$ to $5.3 \pm 2.6(\mathrm{P}<0.001)$ for the maximum value (Figure 1). A maximum improvement in pain intensity of more than two points between the first and last recorded visit was noted in $73.2 \%$ of patients. This two-point improvement was noted at the second visit in $65.6 \%$ of cases. For 294 completed dossiers, $45.5 \%$ of patients had a pain intensity reduction of more than $50 \%$, and $82.2 \%$ had a decrease of at least $30 \%$ (Table 2). Only $7.5 \%$ of patients noted no improvement. In the population older than 70 years of age, $54.4 \%$ of patients experienced a pain intensity decrease of more than $50 \%$, and $83.8 \%$ a decrease of at least $30 \%$; only $11.8 \%$ of the patients showed no improvement (Table 2).

The reduction in analgesic consumption was statistically significant: 13.2\% ( $\mathrm{P}<0.0001)$ for WHO step I, 23.7\% ( $<<0.0001)$ for step II and $9.1 \%(\mathrm{P}<0.0001)$ for step III analgesics (Table 3$)$. The reduction was even greater in the population older than 70 years of age, with a $16.7 \%$ benefit for step I $(\mathrm{P}=0.0011)$ and $32.4 \%$ for step II $(\mathrm{P}<0.0001)$, but a moderate and nonsignificant improvement for step III analgesics (4.9\%; $\mathrm{P}=0.37)$. The reduction was also significant for coanalgesics for neuropathic pain: for tricyclic antidepressants, it was $14.9 \%$ $(\mathrm{P}<0.0001)$, for antiepileptics $20.8 \%(\mathrm{P}<0.0001)$ and for serotonin reuptake inhibitors $4.9 \%(\mathrm{P}=0.005)$. In the population older than 70 years of age, the reduction was significantly greater for tricyclic antidepressants (17.7\%; P=0.001) and antiepileptics (25.5\%; $\mathrm{P}<0.0001$ ), but nonsignificant for selective serotonin reuptake inhibitors $(2.9 \% ; \mathrm{P}=0.32$; Table 3$)$.

Treatment-related adverse effects were recorded for 39 patients or $9.0 \%$ of the population, and were the cause of treatment discontinuation in $3 \%$. The most common effects were erythema $(n=19)$, pruritis $(n=11)$, burns $(n=12)$ and edema $(n=4)$. 
TABLE 3

\begin{tabular}{|c|c|c|c|c|}
\hline \multirow[b]{2}{*}{ Treatments } & \multicolumn{2}{|c|}{$\begin{array}{l}\text { Total population } \\
\qquad(n=431)\end{array}$} & \multicolumn{2}{|c|}{$\begin{array}{c}\text { Age }>70 \text { years } \\
\quad(n=102)\end{array}$} \\
\hline & $\%$ & $\mathbf{P}$ & $\%$ & $\mathbf{P}$ \\
\hline Antiepileptics & -20.8 & $<0.0001$ & -25.5 & $<0.0001$ \\
\hline At least 1 antidepressant & -16.5 & $<0.0001$ & -18.6 & 0.0009 \\
\hline Tricyclic & -14.9 & $<0.0001$ & -17.7 & 0.001 \\
\hline SSRI & -4.9 & 0.005 & -2.9 & 0.32 \\
\hline \multicolumn{5}{|l|}{ Analgesics } \\
\hline Step I & -13.2 & $<0.0001$ & -16.7 & 0.001 \\
\hline Step II & -23.7 & $<0.0001$ & -32.4 & $<0.0001$ \\
\hline Step III & -9.1 & $<0.0001$ & -4.9 & 0.37 \\
\hline
\end{tabular}

$P$ values correspond to McNemar test. All analgesic treatments were administered alone or in combination. SSRI Selective serotonin reuptake inhibitor

\section{DISCUSSION}

The present article describes the follow-up of neuropathic pain patients in specialized units. Although retrospective, the study made it possible to assess the value of $5 \%$ lidocaine-medicated plaster in patients with neuropathic pain who met precise clinical criteria (diagnosis, etiology and therapy) and represents a preliminary stage before a prospective clinical evaluation.

It was performed five years after the first prescriptions for $5 \%$ lidocaine-medicated plaster (2001); hence, the late and restricted use of the DN4 questionnaire, which became available in 2005, and the lack of information about some comorbidity parameters more readily identified today, such as depression, anxiety, sleep disorders and other associated conditions. Incomplete identification of sensory deficits or evoked pain has to be regarded in the context of the use of nonstandardized documentation. However, these results provide an opportunity for therapists to improve the management of pain, its evaluation and follow-up by use of more homogeneous dossier content.

\section{Population}

The large cohort of 467 patients recruited from an urban and rural population is representative of patients consulting a specialized pain centre for refractory chronic pain conditions. The age, sex and activities of the present population were similar to those investigated during recent epidemiological studies conducted in France and in Europe $(1,2,20)$. Approximately $25 \%$ of patients were older than 70 years of age.

Equal numbers of patients were referred by general practitioners and specialists. There may be several reasons for elderly patients mainly being referred by general practitioners, and young people by consultant orthopedists. In the case of young people, for example, one reason may have been the prevalence of localized postsurgical or post-traumatic neuropathic lesions, with an early onset that is responsible for considerable disability and that compromises the short-term outcome and resumption of activity as well as long-established collaborations with the surgical teams.

\section{Neuropathic pain}

The main indication for treatment with 5\% lidocaine-medicated plaster was peripheral neuropathic pain; only 13 patients with central pain were included because of the very limited painful and allodynic area. The clinical characteristics of patients' neuropathic pain were consistent with the inclusion criteria and the indication for topical treatment - allodynia, burning and electric shock-type pain were reported in most cases. The diagnosis of neuropathic pain was also defined as a DN4 score of greater than 4 . This was used by a small number of patients $(n=81)$ because it became available relatively late in the course of the investigation. The score of greater than 4 correlated particularly well with the high incidence of allodynia. The
French version of the McGill Pain Questionnaire (18) is not a specific diagnostic tool for neuropathic pain, but the items that are reported with a high prevalence in neuropathic pain patients in the literature $(19,21)$ - ie, burning, crushing, electric shock-type pain, etc - were also frequently observed.

Regarding the etiology of neuropathic pain, the incidence of PHN in the population older than 70 years of age was higher, as is classically described (22). Most patients did not have PHN (only 20.6\%), but a localized neuropathic pain syndrome with allodynia. The etiologies most often reported were trauma and surgery, with a clear majority of orthopedic patients. The pain could be mixed (ie, possess both nociceptive and neuropathic components), but in every case it met the criteria for neuropathic pain. This justifies the indication for $5 \%$ lidocaine-medicated plasters, which were prescribed against a background of refractory pain (failure or intolerance to previous therapies), ie, the neuropathic pain had the same symptomatic expression pattern as PHN. The lower prevalence of cancer pain in the present observational study group was not consistent with epidemiological or literature data (23-25). This can be partly explained by the fact that cancer pain in France is often managed outside of pain centres, and also that mixed pain is not identified sufficiently often in cancer patients. Pain caused by diabetic neuropathy is a peripheral polyneuropathy that is not usually treated with $5 \%$ lidocaine-medicated plasters in France, unlike in other European countries (14).

All patients in the present study had been treated for neuropathic pain with analgesic treatment that was insufficiently effective or poorly tolerated before a complementary topical treatment was prescribed. The number of previous therapies was high (two to five in three-quarters of the patients).

\section{Efficacy}

The decrease in NRS scores from the initial high levels ( 5 to 8; due to the failure of previous treatment) showed that the reduction in pain intensity was statistically and clinically significant for both the minimum and the maximum values. The high percentage $(73.2 \%)$ of patients relieved by more than two NRS points corroborated the significance of this treatment effect (26). The efficacy evaluation at one month was predictive of efficacy $(68 \%)$ at following visits, and justified the therapeutic testing routinely performed in clinical practice, ie, a test after one month of treatment to consider whether it should continue.

Efficacy was also confirmed by the high $30 \%$ and $50 \%$ responder rates. The significance of these values has been accepted in many studies (27). These results are particularly satisfactory because treatment had failed in the selected population.

A reduction in drug consumption was observed in all population samples and especially in the elderly, high-risk - often polymedicated - population. The benefit was particularly high for step II analgesics and the population older than 70 years of age, with its well-documented risks of adverse drug reactions and iatrogenic problems $(28,29)$. There was also a significant reduction in the consumption of coanalgesics for neuropathic pain such as antidepressants, antiepileptics and psychotropics. Although these agents have a relatively satisfactory number needed to treat in these complex therapeutic situations, they often give rise to severe adverse effects (number needed to harm) $(30,31)$ and poor compliance, particularly in the elderly population (32)

Tolerability was good; only minor adverse reactions were related to the use of $5 \%$ lidocaine-medicated plaster, similar to results reported in the literature. The mean duration of treatment, performed at a given time in patients who had received this therapy during the five-year inclusion period, was difficult to analyze by retrospective analysis.

The mean dose used of approximately one plaster/day was very similar to doses reported in the literature $(9,14)$, and demonstrates an economic advantage compared with the average cost of the other medicinal products proposed (33). The results suggest that this plaster provides benefit by reducing the prescription of other analgesics and 
reducing morbidity; many of the prescriptions authorized by health authorities within the scope of the named-patient program were justified because of major adverse reactions. This is particularly true of the high-risk elderly population and in those with impaired vital functions (renal, hepatic, cardiovascular insufficiency, etc) (34).

\section{CONCLUSION}

The present retrospective study investigated a large population of patients, diverse in terms of age, place of residence, profession and patient care pathway, who were suffering from refractory, chronic neuropathic pain and had been referred to a specialized pain centre. From an epidemiological standpoint, the patients who benefitted most from therapy with 5\% lidocaine-medicated plaster were those who presented with postsurgical and/or post-traumatic localized neuropathic pain, in whom more usual therapies provided inadequate pain relief or produced adverse reactions. Observational study of our clinical practices analyzed the value of this therapy, which has been recommended as a first-line treatment by certain expert groups $(4,27)$ as part of our treatment armamentarium for localized neuropathic pain.

We were able to conduct a de facto analysis of the clinical impression during empirical use of this topical treatment. The results clearly demonstrate efficacy and an excellent safety profile with very few local adverse reactions, as well as a simplification of treatment patterns and a reduction in concomitant medication. The next step is to confirm these results for different etiologies in complementary prospective studies and to demonstrate a good benefit-risk ratio in specific populations.

ACKNOWLEDGEMENTS: The authors thank Derrick Garwood Ltd, Cambridge, United Kingdom, for editorial support, which was sponsored by Grünenthal GmbH, Aachen, Germany.

\section{REFERENCES}

1. Bouhassira D, Lantéri-Minet M, Attal N, Laurent B, Touboul C. Prevalence of chronic pain with neuropathic characteristics in the general population. Pain 2008;136:380-7.

2. Haute Autorité de Santé. Douleur chronique: Reconnaître le syndrome douloureux chronique, l'évaluer et orienter le patient. December 2008. <www.pediadol.org/article-imprim.php3?id_ article $=920>$ (Accessed on June 15, 2011).

3. Deshpande MA, Holden RR, Gilron I. The impact of therapy on quality of life and mood in neuropathic pain: What is the effect of pain reduction? Anesth Analg 2006;102:1473-9.

4. Finnerup NB, Otto M, McQuay HJ, Jensen TE, Sindrup SH. Algorithm for neuropathic pain treatment: An evidence based proposal. Pain 2005;118:289-305.

5. Attal N, Cruccu G, Haanpaa M, et al. EFNS guidelines on pharmacological treatment of neuropathic pain. Eur J Neurol 2006;13:1153-69.

6. Dworkin RH, O'Connor AB, Backonja M, et al. Pharmacologic management of neuropathic pain: Evidence-based recommendations. Pain 2007;132:237-51.

7. Rowbotham MC, Davies PS, Verkempinck C, Galer BS. Lidocaine patch: Double-blind control study of a new treatment method for post-herpetic neuralgia. Pain 1996;65:39-44.

8. Galer BS, Rowbotham MC, Perander G, Friedman E. Topical lidocaine patch relieves post-herpetic neuralgia more effectively than a vehicle topical patch: Results of an enriched enrolment study. Pain 1999;80:533-8.

9. Binder A, Bruxelle J, Rogers P, et al. Topical 5\% lidocaine (lignocaine) medicated plaster treatment for post-herpetic neuralgia: Results of a double-blind, placebo-controlled, multinational efficacy and safety trial. Clin Drug Invest 2009;29:393-408.

10. Gilron I, Watson PN, Cahill CM, Moulin DE. Neuropathic pain: A practical guide for the clinician. CMAJ 2006;175:265-75.

11. O'Connor AB, Dworkin RH. Treatment of neuropathic pain: An overview of recent guidelines. Am J Med 2009;122:S22-32.
12. Hempenstall K, Nurmikko TJ, Johnson RW, A'Hern RP, Rice ASC. Analgesic therapy in postherpetic neuralgia: A quantitative systematic review. PLoS Med 2005;2:628-44.

13. Katz NP, Gammaitoni AR, Davis MW, Dworkin RH Lidocaine patch $5 \%$ reduces pain intensity and interference with quality of life in patients with postherpetic neuralgia: An effectiveness trial. Pain Med 2002;3:324-32.

14. Meier T, Wasner G, Faust M, et al. Efficacy of lidocaine patch 5\% in the treatment of focal peripheral neuropathic pain syndromes: A randomized, double-blind, placebo controlled study. Pain 2003;106:151-8.

15. Argoff CE, Galer BS, Jensen MP, Oleka N, Gammaitoni AR. Effectiveness of the lidocaine patch $5 \%$ on pain qualities in three chronic pain states: Assessment with the Neuropathic Pain Scale. Curr Med Res Opin 2004;20(Suppl 2):S21-8.

16. Burch F, Codding C, Patel N, Sheldon E. Lidocaine patch 5\% improves pain, stiffness, and physical function in osteoarthritis pain patients. A prospective, multicenter, open-label effectiveness trial. Osteoarthritis Cartilage 2004;12:253-5.

17. Melzack R. The McGill Pain Questionnaire: Major properties and scoring methods. Pain 1975;1:277-99.

18. Boureau F, Luu M, Doubrere JF, Gay C. Elaboration d'un questionnaire d'auto-évaluation de la douleur par liste de qualificatifs. Comparaison avec le McGill Pain Questionnaire de Melzack. Thérapie 1984;39:119-39.

19. Bouhassira D, Attal N, Alchaar H, et al. Comparison of pain syndromes associated with nervous or somatic lesions and development of a new neuropathic pain diagnostic questionnaire (DN4). Pain 2005;114:29-36.

20. Torrance N, Smith BH, Bennett MI, Lee AJ. The epidemiology of chronic pain of predominantly neuropathic origin. Results from a general population survey. J Pain 2006;7:281-9.

21. Bennett MI, Attal N, Backonja MM, et al. Using screening tools to identify neuropathic pain. Pain 2007;127:199-203.

22. Dworkin RH, Gnann JW, Oaklander AL, et al. Diagnosis and assessment of pain associated with herpes zoster and post herpetic neuralgia. J Pain 2008;9:37-44.

23. Larue F, Colleau SM, Brasseur L, Cleeland CS. Multicentre study of cancer pain and its treatment in France. BMJ 1995;310:1034-7.

24. Hearn J, Higginson IJ. Cancer pain epidemiology: A systematic review. In: Bruera ED, Portenoy RK, eds. Cancer pain: Assessment and management. New York: Cambridge University Press, 2003:19-37.

25. Van den Beuke-van Everdingen MHJ, de Rijke JM, Kessels AG, et al. Prevalence of pain in patients with cancer: A systematic review of the past 40 years. Ann Oncol 2007;18:1437-49.

26. Farrar JT, Portenoy RK, Berlin JA, Kinman JL, Strom BL. Defining the clinically important difference in pain outcomes measures. Pain 2000;88:287-94.

27. Dworkin RH, Turk DC, Wyrwich KW, et al. Interpreting the clinical importance of treatment outcomes in chronic pain clinical trials: IMMPACT recommendations. J Pain 2008;9:105-21.

28. Sindrup SH, Otto M, Finnerup NB, Jensen TS. Antidepressants in the treatment of neuropathic pain. Basic Clin Pharmacol Toxicol 2005;96:399-409.

29. Rosenzweig-Lipson S, Beyer CE, Hughes ZA, et al. Differentiating antidepressants of the future: Efficacy and safety. Pharmacol Ther 2007;113;134-53.

30. Wiffen PJ, McQuay HJ, Edwards JE, Moore RA. Gabapentin for acute and chronic pain. Cochrane Database Syst Rev 2005;(3):CD005452.

31. Saarto T, Wiffen PJ. Antidepressants for neuropathic pain. Cochrane Database Syst Rev 2007;(4):CD005454.

32. Roose SP. Compliance: The impact of adverse events and tolerability on the physician's treatment decisions. Eur Neuropsychopharmacol 2003;13:85-92.

33. Dakin H, Nuijten M, Liedgens H, Nautrup BP. Cost-effectiveness of a lidocaine $5 \%$ medicated plaster relative to gabapentin for post-herpetic neuralgia in the United Kingdom. Clin Ther 2007;29:1491-507.

34. Gore M, Dukes E, Rowbotham DJ, Tai KS, Leslie D. Clinical characteristics and pain management among patients with painful peripheral neuropathic disorders in general practice settings. Eur J Pain 2007;11:652-64. 


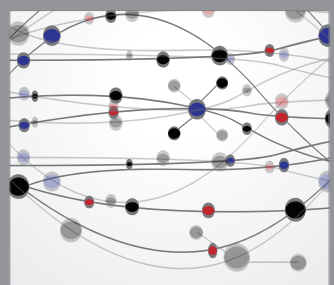

The Scientific World Journal
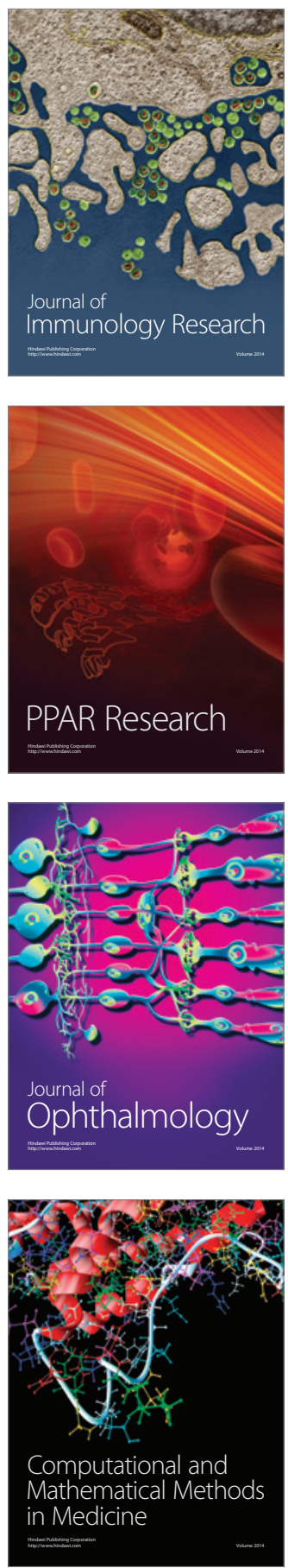

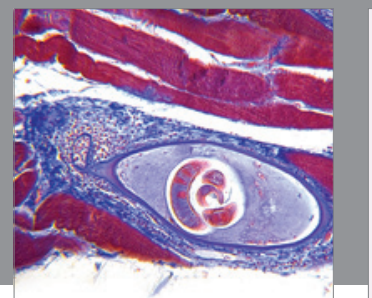

Gastroenterology

Research and Practice
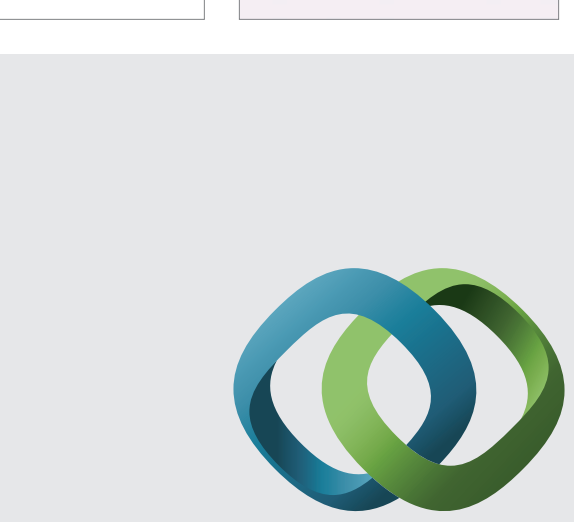

\section{Hindawi}

Submit your manuscripts at

http://www.hindawi.com
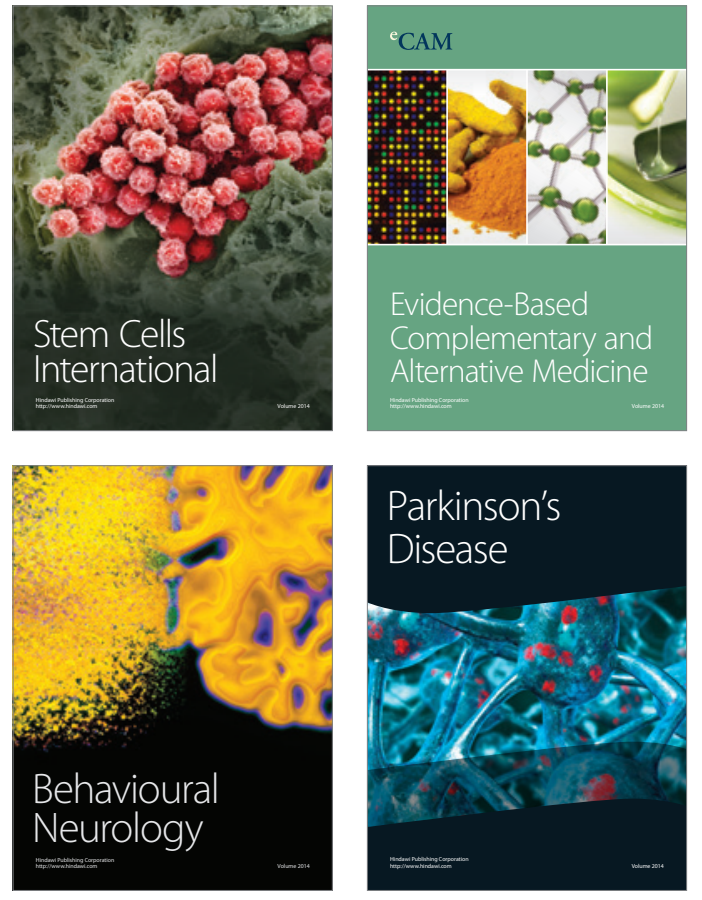
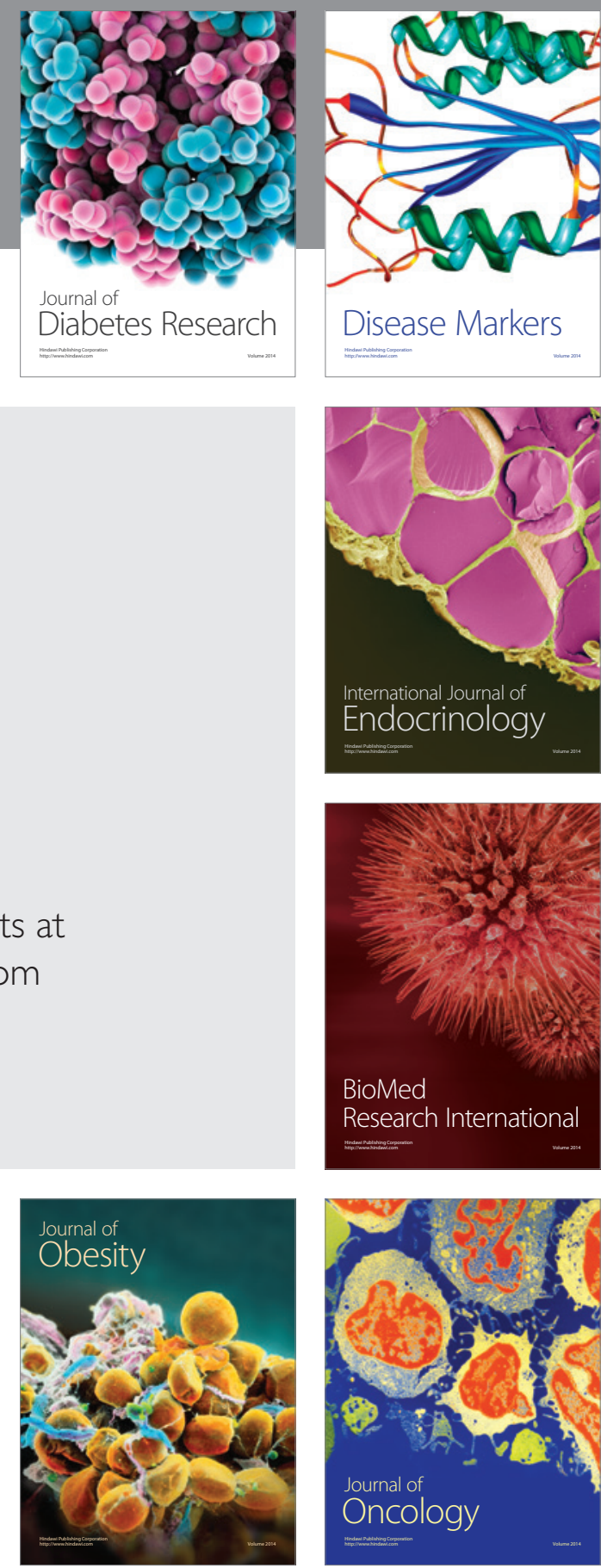

Disease Markers
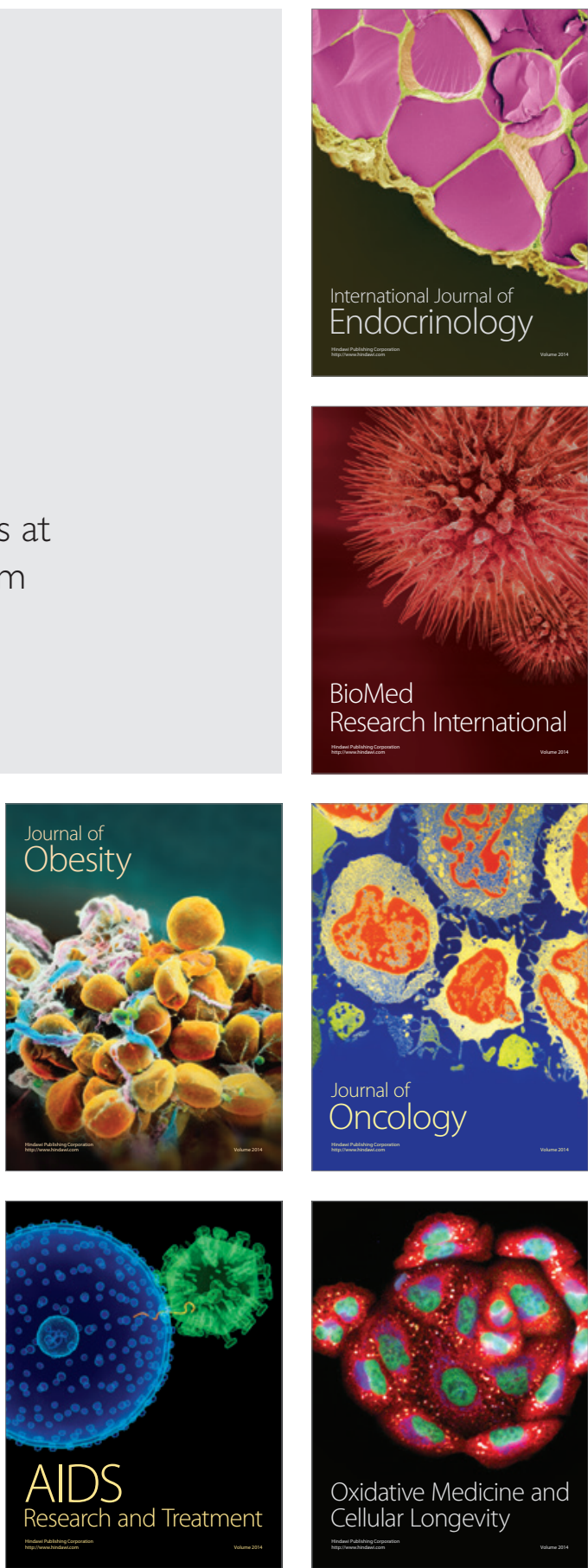